\title{
Acceleration of cardiovascular-biological age by amphetamine exposure is a power function of chronological age
}

\author{
Albert Stuart Reece, Amanda Norman, Gary Kenneth Hulse
}

- Additional material is available. To view please visit the journal online (http://dx. doi.org/10.1136/heartasia2016-010832)

School of Psychiatry and Clinical Neurosciences, University of Western Australia, Crawley, Western Australia, Australia

\section{Correspondence to} Associate Professor Albert Stuart Reece, 39 Gladstone Rd., Highgate Hill, Brisbane, Queensland, 6008 Australia sreece@bigpond.net.au

Received 1 September 2016 Revised 5 November 2016 Accepted 7 November 2016

\section{CrossMark}

To cite: Reece $A S$ Norman A, Hulse GK. Heart Asia 2017:9:30-38.

doi:10.1136/heartasia-2016010832

\section{ABSTRACT}

Background Amphetamine abuse is becoming more widespread internationally. The possibility that its many cardiovascular complications are associated with a prematurely aged cardiovascular system, and indeed biological organism systemically, has not been addressed. Methods Radial arterial pulse tonometry was performed using the SphygmoCor system (Sydney). 55 amphetamine exposed patients were compared with 107 tobacco smokers, 483 non-smokers and 68 methadone patients (total=713 patients) from 2006 to 2011. A cardiovascular-biological age (VA) was determined. Results The age of the patient groups was 30.03 $\pm 0.51-40.45 \pm 1.15$ years. This was controlled for with linear regression. The sex ratio was the same in all groups. $94 \%$ of amphetamine exposed patients had used amphetamine in the previous week. When the (log) VA was regressed against the chronological age (CA) and a substance-type group in both cross-sectional and longitudinal models, models quadratic in CA were superior to linear models (both $p<0.02$ ). When log VA/ CA was regressed in a mixed effects model against time, body mass index, CA and drug type, the cubic model was superior to the linear model $(p=0.001)$. Interactions between $C A,(C A)^{2}$ and $(C A)^{3}$ on the one hand and exposure type were significant from $p=0.0120$. The effects of amphetamine exposure persisted after adjustment for all known cardiovascular risk factors $(p<0.0001)$.

Conclusions These results show that subacute exposure to amphetamines is associated with an advancement of cardiovascular-organismal age both over age and over time, and is robust to adjustment. That this is associated with power functions of age implies a feed-forward positively reinforcing exacerbation of the underlying ageing process.

\section{INTRODUCTION}

With the use of psychostimulants increasing in many countries to the particular concern of the United Nations, ${ }^{1}$ further study of their pharmacological effects in a naturalistic environment is timely. While amphetamines are best known for their prominent clinical effects of neuropsychiatric stimulation, they are also known to have stimulant effects on other body systems. This is particularly true of the cardiovascular system where they are known to have many haemodynamic and pathological effects including accelerated pulse rate, increased central systolic pressure, increased central pulse pressure, accelerated atherosclerosis including coronary atherosclerotic disease, hypertensive crises, cerebrovascular accidents, ruptured cerebral and thoracic arterial aneurysms, dissecting aneurysms and many tachyarrythmias including sudden cardiac death. ${ }^{2}$

The abuse of stimulants is presumably stressful on the cardiovascular system over time. However there are very few studies of such processes in living humans. Widely publicised photographs of stimulant abusers are well known to show very rapid apparent ageing and such individuals died soon after these photographs were taken (see http:// www.telegraph.co.uk/news/uknews/1475611/

Snapshots-from-hell-images-aimed-at-addicts.html). The possibility exists then that the acute cardiovascular events for which amphetamine is so well known, do not occur de novo, but on the background of prior cardiovascular degeneration and ageing. It may be that the crisis events occur in a system already stressed and aged by prior sympathetic overdrive and hyperadrenalism, just as is seen in the changes in the skin. However there are few studies of such changes in life.

Withdrawal from opioids is known to stimulate the sympathoadrenal system, and to be associated with adrenaline surges which may bear similarities to those induced by exogenous abuse of stimulants. Our group has previously documented the cardiovascular stress and parameters of increased central augmented haemodynamic pressures experienced by patients in opioid withdrawal. ${ }^{3}$ It may be therefore that psychostimulant abuse bears some similarities with recurrent opioid withdrawal, as is common among patients addicted to short-term opioids.

The increasing measurement of in vivo arterial stiffness, and its direct corollary cardiovascular age, implies that such changes are measurable clinically. As it is recognised that vascular age (VA) is the primary determinant of organismal biological age, ${ }^{45}$ the clinical and investigative power of these studies is obviously considerable. This implies that in addition to making measurements of central haemodynamics, VA, as a major surrogate of organismal age ${ }^{45}$ can also be derived concurrently.

As our clinic sees both general medical patients along with patients addicted to stimulants and opioids, and has access to the AtCor SphygmoCor device for cardiovascular assessment, it was considered that we were ideally placed to investigate this issue. Cocaine use is still rare in Australia, so that the stimulant abusers seen in our clinic were users of amphetamine derivatives, known on the street as 'Speed', 'Ice' and 'Ecstasy'. The following documents our demonstration of accelerated cardiovascular ageing in patients with a recent and current 
history of amphetamine abuse, and is in accordance with the concept that such patients are ageing their cardiovasculature both subacutely and/or chronically. As no similar reports, to our knowledge, are in existence, this is the first report of its type.

\section{METHODS}

\section{Patient selection}

Patients who reported amphetamine use were studied at the time of their presentation to the clinic. Other patients were studied opportunistically as they were seen for the usual medical management. Patients were not considered in the present analysis with any condition which may have altered cardiovascular function. Hence patients with known cardiovascular disease, pregnancy, drug withdrawal, acutely affected by heroin or cannabis or with acute infection were not included. Patients on methadone were considered separately as a comparator group. The study was conducted during 2006-2011 in Brisbane, Australia.

\section{Radial arterial pulse wave tonometry}

Patients reclined quietly on a bed during the study. They were not allowed to sleep, but were not prevented from smoking, eating or drinking prior to the study. The brachial blood pressure was taken with an Omron HEM-907 sphygmomanometer usually on the left arm. The AtCor SphygmoCor system was used to conduct the Radial Arterial Pulse Wave Tonometry (RAPWT) Study including a Miller micromanometer inside a handheld probe. To be accepted studies were required to be technically satisfactory and to have an Operator Index of 70 or more. Studies were all performed in quintuplicate. Among the many parameters produced by the system the software calculates a VA reference age by an algorithm matching the degree of arterial stiffening with age, sex and height.

\section{Demographic and laboratory data}

Patients were asked about their prior drug use at the time of the performance of the pulse wave tonometry. When asked to quantify their use of psychostimulants patients generally gave vague and variable answers. Use was invariably quantified as 'points'. Frequency was often vague and highly variable such as once or twice a week with many periods in and out of active use. The clinical pathology testing for our clinic is done by Queensland Medical Laboratories (QML). QML is accredited to both the International Laboratory Standard ISO-9001 and by the National Association of Testing Laboratories to Australian Standard AS-15189.

\section{Statistics}

Data from the above sources were collated into a Microsoft Excel spreadsheet. Categorical data were studied with EpiInfo 7.1.4.0 from Centres for Disease Control, Atlanta, Georgia, USA. Statistica 7.1 from Statsoft Tulsa, Oklahoma, USA was used to compute bivariate group differences. Student's t-tests were all two tailed. The statistical program ' $R$ ' was used to compute multiple regression calculations. 'R' was downloaded from the Cloud Central R Archive Network mirror and the packages base, ggplot2, reshape and nlme were used. Continuous variables were log transformed as indicated by the Shapiro test to comply with normality assumptions. Repeated measures mixed effects models for time dependent variables were employed using unity and the patient's unique identified code as random effects using Restricted Estimators of Maximum Likelihood. Models were compared using analysis of variance (ANOVA) methods. Mixed effects models were compared in their maximum likelihood mode in ANOVA models. Missing data were handled by casewise deletion. Initial models were reduced by the classical method with successive deletion of the least significant terms until only significant terms remained. A value of $\mathrm{p}<0.05$ was considered significant.

\section{Ethics}

Patients gave informed consent for the conduct of RAPWT and for the inclusion of their anonymised data in the current deidentified analysis. The Human Research Ethics Committee of the Southcity Medical Centre gave formal ethical approval for the study. This committee has been registered with the National Health and Medical Research Council in Australia. The conduct of the study complied with the Declaration of Helsinki.

\section{RESULTS}

As shown in table 1 this study reviewed 713 patients in four groups. There were 483 in the non-smoking control group, 107 in the tobacco smoking group, 55 in the amphetamine group and 68 in the methadone group. Methadone was included as a positive control as has previously been described. ${ }^{6}$ These 713 patients were studied on 953 occasions as indicated in the table. As shown in table 1 there were significant age differences between the groups. However the sex ratios were not dissimilar. The average buprenorphine dose among the amphetamine patients was $12.42 \pm 4.87 \mathrm{mg}$ and the average methadone dose among the methadone exposed patients was $64.18 \pm 4.09 \mathrm{mg}$. Other differences between the groups are shown in table 1 .

It is of interest that the time since amphetamine use was also noted. The mean period since amphetamine use was 5.8 \pm 1.91 days (median 2 days, mode 1 day). Of the 66 occasions on which RAPWT was performed and for which meaningful responses to amphetamine use was obtained, 62 exposures (93.9\%) had occurred within the previous week, and 31 (47\%) had occurred the day prior.

Table 2 shows differences in the cardiovascular parameters considered on a bivariate basis. The methadone group is noted to have significantly advanced augmentation indices, but this is partly related to their older age (table 1 ). The heart rate in the stimulant patients is higher which also affects some of the timing indices.

Online supplementary table S1 lists some of the clinical laboratory differences between the groups.

Figure 1 shows various age related cardiovascular parameters as a function of chronological age (CA). Figure 2 shows these same parameters over time. Online supplementary figure S1 shows some of the other cardiovascular parameters as a function of age and online supplementary figure S2 illustrates the same group of factors over time.

In order to confirm that the amphetamine exposed patients exhibited increased VA, linear regression was performed to adjust for age. In the cross-sectional study linear regression was performed of the VA against CA and the drug exposure category. A model quadratic in CA was shown to fit the data better than a linear model (residual sum of squares (RSS) 65.68 and 66.32, $\mathrm{DF}=1, \mathrm{~F}=6.203, \mathrm{p}=0.013$ ). The final model is shown in the top part of table 3. A significant interaction between the square of CA and amphetamine exposure is noted $(p=0.0210)$.

The same question was considered in the longitudinal sample. Again a model quadratic in age was a superior fit to the data compared with a linear mixed effects model (akaike information criterion $(\mathrm{AIC})=372.89$ and 377.48 , likelihood ratio=6.597, $\mathrm{p}=0.0102$ ). In this model, shown in the middle portion of table 3, an interaction between age and amphetamine exposure was again significant $(p=0.0215)$. The issue was also investigated 
Table 1 Demographic and drug use data

\begin{tabular}{|c|c|c|c|c|c|c|c|}
\hline \multirow[b]{2}{*}{ Parameter } & \multicolumn{4}{|c|}{ Data (mean (SEM)) } & \multicolumn{3}{|c|}{ Bivariate Student's t-tests $p$ values } \\
\hline & $\begin{array}{l}\text { Amphetamine } \\
\text { (55) }\end{array}$ & $\begin{array}{l}\text { Non-smokers } \\
\text { (483) }\end{array}$ & $\begin{array}{l}\text { Tobacco } \\
(107)\end{array}$ & $\begin{array}{l}\text { Methadone } \\
\text { (68) }\end{array}$ & Amphet-control & Amphet-tobacco & Amphet-methadone \\
\hline \multicolumn{8}{|l|}{ Anthropometrics } \\
\hline Age & $34.44(1.13)$ & $30.03(0.51)$ & $30.76(0.97)$ & $40.45(1.15)$ & 0.0046 & 0.2574 & $<0.0001$ \\
\hline Male sex, n (\%) & $38(69.1)$ & $335(69.4)$ & $77(72.0)$ & $42(62.8)$ & 0.9095 & 0.8425 & 0.5111 \\
\hline Longitudinal study, n & 88 & 651 & 128 & 86 & & & \\
\hline Height & $174.58(1.09)$ & $173.56(0.40)$ & $174.63(0.82)$ & $171.7(1.15)$ & 0.4103 & 0.6136 & 0.8200 \\
\hline Weight & $76.75(2.02)$ & $73.2(0.64)$ & $75.51(1.40)$ & $77.43(2.14)$ & 0.0810 & 0.5039 & 0.2549 \\
\hline Body mass index & $25.16(0.60)$ & $24.26(0.19)$ & $24.69(0.39)$ & $26.16(0.62)$ & 0.1296 & 0.0499 & 0.0020 \\
\hline \multicolumn{8}{|l|}{ Drug use } \\
\hline Cigarettes/day & $17.45(1.74)$ & & $11.86(0.89)$ & $15.85(1.31)$ & $<0.0001$ & 0.9049 & 0.0205 \\
\hline Years of tobacco & $15(3.21)$ & & 16 & $25.9(2.03)$ & 0.9049 & 0.6085 & 0.2223 \\
\hline Packet-years tobacco & $15.8(4.56)$ & & 9.6 & $27.86(4.62)$ & 0.2302 & 0.0003 & 0.0223 \\
\hline Minutes after tobacco & $53.92(18.96)$ & & $257.86(50.31)$ & $163.25(42.84)$ & 0.6781 & 0.9744 & 0.0715 \\
\hline Heroin, dose (g/day) & $0.45(0.07)$ & & $0.05(0.02)$ & $0.98(0.18)$ & $<0.0001$ & $<0.0001$ & $<0.0001$ \\
\hline Heroin, duration (years) & $9.32(1.26)$ & $0.06(0.06)$ & $1.13(0.45)$ & $19.95(1.34)$ & $<0.0001$ & $<0.0001$ & 0.0057 \\
\hline $\begin{array}{l}\text { Heroin, dose-duration } \\
\text { (g-year) }\end{array}$ & $6.07(1.01)$ & $0.03(0.03)$ & $0.39(0.18)$ & $23.6(6.04)$ & $<0.0001$ & 0.0018 & 0.4540 \\
\hline
\end{tabular}

in the longitudinal study with mixed effects models by regressing (log) VA/CA against CA, time, body mass index (BMI) and drug use status in models including polynomial terms in CA. The model cubic in CA was noted to be better than the linear model (AICs 303.734 and 311.085, likelihood ratio=39.34 and $\mathrm{p}=0.001$ ). As shown in the bottom portion of table 3 , interactive terms including amphetamines were significant with the square and cube of CA from $\mathrm{p}=0.0120$.

Because of the uncertainty and variability of the drug use histories it was not possible to quantitate amphetamine use meaningfully. Thus dose-response studies could not be calculated.

It was also of interest to examine the acute effect of time since exposure on the VA/CA ratio. This relationship is shown in figure 3 and in table 4. There was no direct correlation between the log (VA/CA) (Spearman's $S=56115, \mathrm{p}=0.17$ ), but when this ratio was regressed there was a significant relationship with the interaction between the CA and days since amphetamine $(p=0.0296)$, and the days on the study, days since amphetamine and CA which was of borderline significance, as shown in the table 4.

It was nevertheless of interest to see how amphetamine exposure when considered as a factor might interact with traditional cardiovascular variables. This issue was considered in the longitudinal data series by regressing the VA against a model interactive in age, BMI and drug status, with additive terms in systolic pressure, cholesterol, diastolic pressure, high density lipoprotein (HDL), low density lipoprotein (LDL), heart rate and high sensitivity CRP. The data series could not handle more interactions than were included in this model computationally. Erythrocyte sedimentation rate (ESR), blood glucose levels, creatine and estimated glomerular filtration rate (eGFR) were included in exploratory models but as they were routinely dropped early in the exclusion process of non-significant terms during model reduction, they were not included in the initial models which were finally adopted. An attempt was made to include the buprenorphine dose in this regression but the model failed to converge. The terms which remained significant in the final model are shown in table 5. Amphetamine use as a factor was found to be highly significant $(\mathrm{p}<0.0001)$, independent of all known cardiovascular risk factors in this analysis.

\section{DISCUSSION}

This study demonstrates that as measured with the SphygmoCor cardiovascular monitoring system amphetamine abusers do indeed appear to be ageing their cardiovascular system in a more rapid manner with regard both to $\mathrm{CA}$ and over time (figures 1 and 2 and table 3). The process seems to occur more aggressively than with tobacco smoking. It appears to follow a different time course to that of the positive methadone control group. It was also shown that the VA/CA ratio declines with time following amphetamine abuse, thereby showing that the acute effects are significant. Of particular concern, when all other known cardiovascular variables were included, amphetamine exposure remained significant.

Therefore the present results confirm our concerns that amphetamine abuse increases the apparent cardiovascular age at least following subacute exposure and given that the exposures are often protracted, repeated and long-term, implies that the organism is exposed to such effects at least on a behavioural basis and also on a chronic and long-term basis. The technology involved in pulse wave tonometry has been developed over the last 20 years and has been reviewed in detail..$^{7-9}$ The data in this study are not of a type to distinguish fixed damage to the vessel wall compared with increased vasomotor tone, so it is not possible on this data alone to determine if the pathology described is phasic and tonic in nature or static and fixed. From a purely functional perspective this is a somewhat academic distinction as the recurrent nature of the cycles of repeated abuse implies that the system is recurrently subject to severe physiological insults.

From a broader perspective however, the present findings of advanced cardiovascular age in association with stimulant use implies, as described in the introduction, that the organism itself is likely ageing in a more rapid manner. This direct implication of our study is of real concern to all those tasked with protection of the public heath, and public health policy broadly. The implication from the present work is that recurrent habitual amphetamine abuse ages the cardiovasculature, and likely the whole organism generally. It is therefore conceivable that stimulant abusers do physiological and cardiovascular harm. There is no similar body of data of which we are aware showing 
Table 2 Cardiovascular data

\begin{tabular}{|c|c|c|c|c|c|c|c|}
\hline \multirow[b]{2}{*}{ Parameter } & \multicolumn{4}{|l|}{ Data, mean (SEM) } & \multicolumn{3}{|c|}{ Bivariate Student's $\mathrm{t}$-tests $\mathrm{p}$ values } \\
\hline & Amphetamine (55) & Non-smokers (483) & Tobacco (107) & Methadone (68) & Amphet-control & Amphet-tobacco & Amphet-methadone \\
\hline Operator Index & $90.82(0.63)$ & $88.79(0.28)$ & $89.02(0.57)$ & $87.68(0.73)$ & 0.0045 & 0.0211 & 0.0003 \\
\hline \multicolumn{8}{|l|}{ Augmentation Indices } \\
\hline VA & $37.65(2.65)$ & $32.58(0.73)$ & $34.2(1.70)$ & $54.32(2.54)$ & 0.0692 & 0.7845 & 0.0013 \\
\hline VA/CA & $1.08(0.06)$ & $1.1(0.02)$ & $1.09(0.04)$ & $1.34(0.06)$ & 0.6603 & 0.4960 & 0.0007 \\
\hline $\log (\mathrm{VA} / \mathrm{CA})$ & $0(0.02)$ & $0.02(0.01)$ & $0.02(0.01)$ & $0.1(0.02)$ & 0.4150 & 0.9510 & 0.0007 \\
\hline VA-CA difference & $3.26(2.15)$ & $2.51(0.56)$ & $3.41(1.16)$ & $13.82(2.09)$ & 0.7373 & 0.7369 & $<0.0001$ \\
\hline Central Augmentation Index (C_Al) & $111.8(2.68)$ & $111.07(0.89)$ & $110.75(1.77)$ & $128.71(2.31)$ & 0.7943 & 0.6102 & $<0.0001$ \\
\hline Central augmentation pressure @ HR=75 (C_AP) & $3.6(0.85)$ & $3.08(0.26)$ & $3.1(0.55)$ & $8.94(0.74)$ & 0.5207 & 0.1181 & 0.0001 \\
\hline Central augmentation pressure @ HR=75 (C_AP_HR75) & $3.58(0.83)$ & $1.89(0.23)$ & $2.1(0.53)$ & $7.93(0.68)$ & 0.0201 & 0.7735 & $<0.0001$ \\
\hline Central augmented pressure/pulse height ratio (C_AGPH) & $8.29(2.00)$ & $7.65(0.63)$ & $7.61(1.35)$ & $20.56(1.48)$ & 0.7464 & 0.1700 & $<0.0001$ \\
\hline Central augmented pressure/pulse height ratio @ HR=75 (C_AGPH_HR75) & $8.31(1.91)$ & $4.99(0.60)$ & $5.06(1.38)$ & $18.74(1.40)$ & 0.0796 & 0.3988 & 0.0142 \\
\hline Central pulse height (C_PH) & $37.25(0.98)$ & $34.96(0.31)$ & $36.24(0.70)$ & $41.1(1.14)$ & 0.0193 & 0.7917 & 0.0001 \\
\hline Pulse pressure amplification ratio (PPAmpRatio) & $156.4(2.79)$ & $157.17(0.88)$ & $155.72(1.75)$ & $139.06(2.31)$ & 0.7794 & 0.3303 & 0.1469 \\
\hline Peripheral maximal dP/dT & $885.82(26.39)$ & $836.42(7.91)$ & $856.64(16.59)$ & $836.5(21.63)$ & 0.0492 & 0.0171 & 0.1099 \\
\hline \multicolumn{8}{|l|}{ Timing indices } \\
\hline Heart rate (HR) & $74.98(1.87)$ & $69.46(0.52)$ & $69.77(1.05)$ & $71.32(1.28)$ & 0.0060 & 0.0091 & 0.0292 \\
\hline Ejection duration (ED) & $312.73(3.27)$ & $324.63(0.93)$ & $322.76(1.86)$ & $321.62(2.48)$ & 0.0009 & 0.0091 & 0.0292 \\
\hline Central Stoke Stroke Volume Index (C_SVI, Buckberg Index) & $135.42(3.98)$ & $144.34(1.38)$ & $143.04(2.76)$ & $138.81(3.22)$ & 0.0390 & 0.0517 & 0.5001 \\
\hline C Tension Time Index (C_TT) & $2309.85(69.73)$ & $2152.88(17.00)$ & $2154.33(36.71)$ & $2367.49(48.86)$ & 0.0326 & 0.7524 & 0.0360 \\
\hline Central Diastolic Time Index (C_DTI) & $3017.15(73.22)$ & $3012.32(18.34)$ & $2991.67(33.38)$ & $3204.54(53.02)$ & 0.9492 & 0.0254 & 0.1873 \\
\hline Central Pulse Period & $828.75(20.76)$ & $889.22(6.67)$ & $882.77(13.45)$ & $863.03(16.08)$ & 0.0041 & 0.0442 & 0.2750 \\
\hline Central diastolic duration (C_DD) & $516.09(18.47)$ & $564.66(6.10)$ & $560.04(12.30)$ & $541.44(14.46)$ & 0.0114 & 0.1083 & 0.4691 \\
\hline Central ejection duration period (C_ED_PERIOD) & $38.65(0.71)$ & $37.35(0.22)$ & $37.36(0.45)$ & $38.01(0.52)$ & 0.0640 & 0.0876 & 0.4127 \\
\hline Central diastolic duration period (C_DD_PERIOD) & $61.44(0.71)$ & $62.8(0.22)$ & $62.82(0.45)$ & $62.15(0.52)$ & 0.0516 & 0.1039 & 0.4759 \\
\hline \multicolumn{8}{|l|}{ Pressure Indices } \\
\hline Systolic pressure—peripheral (SP) & $127.75(2.30)$ & $123.17(0.52)$ & $123.6(1.03)$ & $129.82(1.83)$ & 0.0573 & 0.2554 & 0.1572 \\
\hline Diastolic pressure—-peripheral (DP) & $70.16(1.81)$ & $68.74(0.41)$ & $67.87(0.86)$ & $73.38(1.41)$ & 0.4464 & 0.1723 & 0.0961 \\
\hline Peripheral mean pressure (P_MEANP) & $88.85(2.02)$ & $86.19(0.43)$ & $85.81(0.89)$ & $92.94(1.35)$ & 0.2020 & 0.1422 & 0.0265 \\
\hline Central systolic pressure (C_SP) & $109.04(2.27)$ & $104.97(0.50)$ & $105.36(0.99)$ & $115.29(1.71)$ & 0.0851 & 0.1891 & 0.2840 \\
\hline Central diastolic pressure (C_DP) & $71.85(1.84)$ & $70.06(0.42)$ & $69.16(0.88)$ & $74.22(1.31)$ & 0.3442 & 0.2403 & 0.0094 \\
\hline Central end systolic pressure (C_ESP) & $95.35(2.27)$ & $92.7(0.51)$ & $92.38(1.04)$ & $102.51(1.61)$ & 0.2618 & 0.1821 & 0.0566 \\
\hline Central mean systolic pressure (C_MPS) & $99.24(2.09)$ & $96.19(0.45)$ & $96.18(0.89)$ & $104.01(1.46)$ & 0.1583 & 0.2323 & 0.1009 \\
\hline Central mean diastolic |pressure (C_MPD) & $82.31(1.96)$ & $80.21(0.43)$ & $79.73(0.88)$ & $86.21(1.31)$ & 0.2992 & 0.1723 & 0.0961 \\
\hline Central mean pressure (C_MEANP) & $88.85(2.02)$ & $86.19(0.43)$ & $85.81(0.89)$ & $92.94(1.35)$ & 0.2017 & 0.4116 & 0.3703 \\
\hline
\end{tabular}

Data are listed as mean $( \pm$ SEM).

$\mathrm{CA}$, chronological age; VA, vascular age. 


\section{Vascular Age (VA) Variables by Chronologic Age by Drug Exposure - Regression Lines}

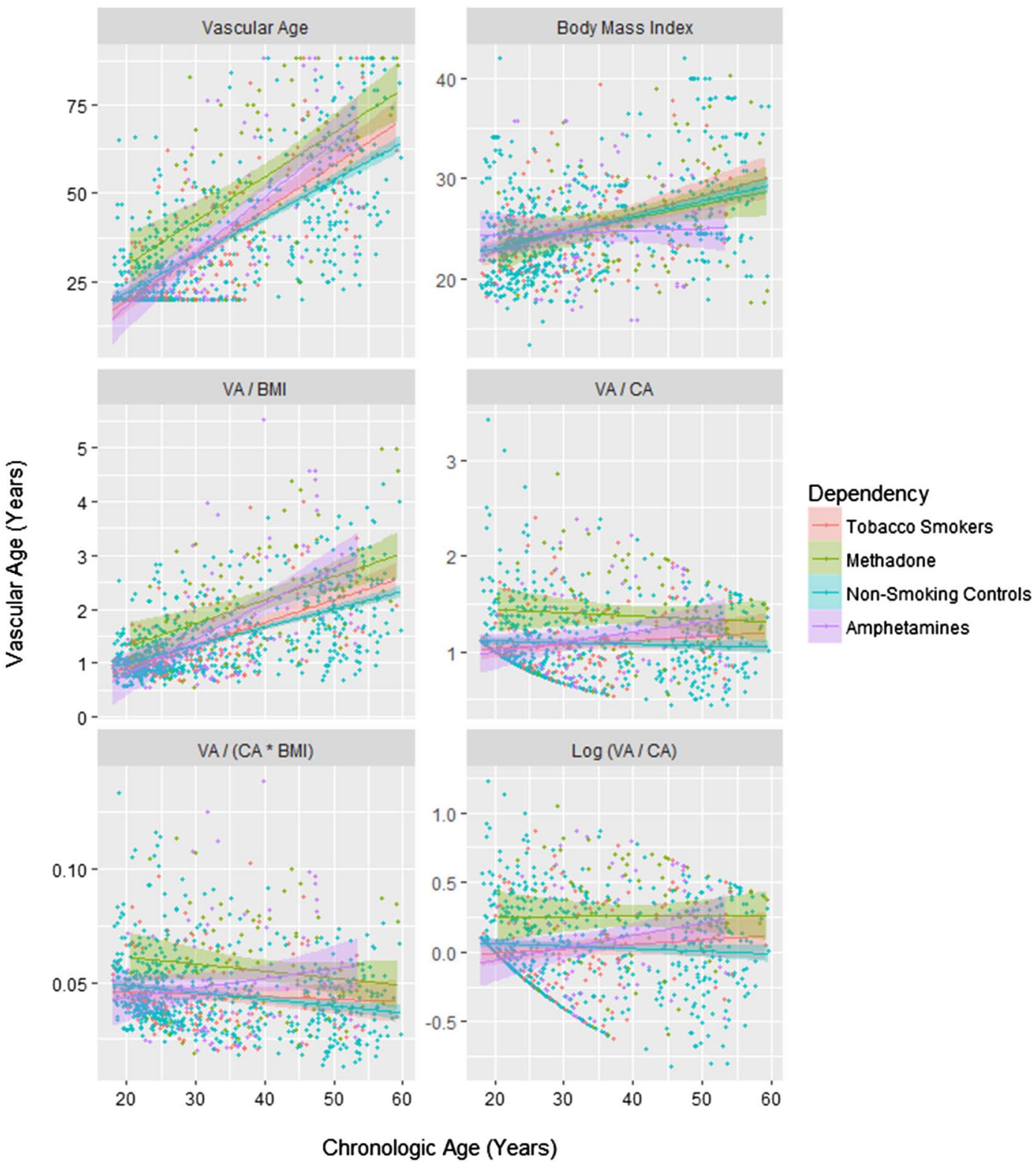

Figure 1 Vascular age by chronological age (CA) and drug exposure type. BMI, body mass index.

remediation of such damage. That is to say, it is not clear to what extent such damage might be reversible.

It was particularly concerning that the best mixed effects regression models consistently showed highly significant interactions between CA and amphetamine exposure. The ageing process itself naturally suggests a power function over time, as many physiological processes fail progressively over the life span. This implies that the effects of stimulant abuse may compound with time, and may become more severe as time progresses and life passes by, which in turn implies that stimulants compound and accelerate the normal time-dependent degeneration of physiological systems. If, as has been demonstrated, the damage from stimulant abuse is actually a power function of time, then this in turn implies that the gathering global stimulant epidemic carries a further message of urgency which has largely not been appreciated. It is a further motivation and impetus for the development of new and novel treatments perhaps including modafinil-class ${ }^{10}$ and naltrexone implants. Opioid withdrawal is an analogus hyperadrenergic state, ${ }^{11}$ and a similar powerful interactive effect has been demonstrated in that condition with CA. ${ }^{3}$

Moreover since stem cells are richly supplied by their microvasculature, and since the microvascular element plays several key roles in stem cell niche function, ${ }^{4}{ }^{12-14}$ it is further likely that an impairment of microvascular functional activity may directly age the stem cell generative niches from which most tissues are renewed. Amphetamines have been shown to interfere with stem cell processes in several tissue beds ${ }^{15} 16$ and to interfere with the machinery of cell division. ${ }^{17}$ Hence amphetamines both impede tissue repair and increase tissue injury through heightened immune activation as noted below, which is a potent negative double entendre and clearly likely to have a strongly progeroid effect with important negative implications for patterns of organismal ageing. Immune stimulation is known to 


\section{Vascular Age (VA) Variables by Time by Drug Exposure - Regression Lines}

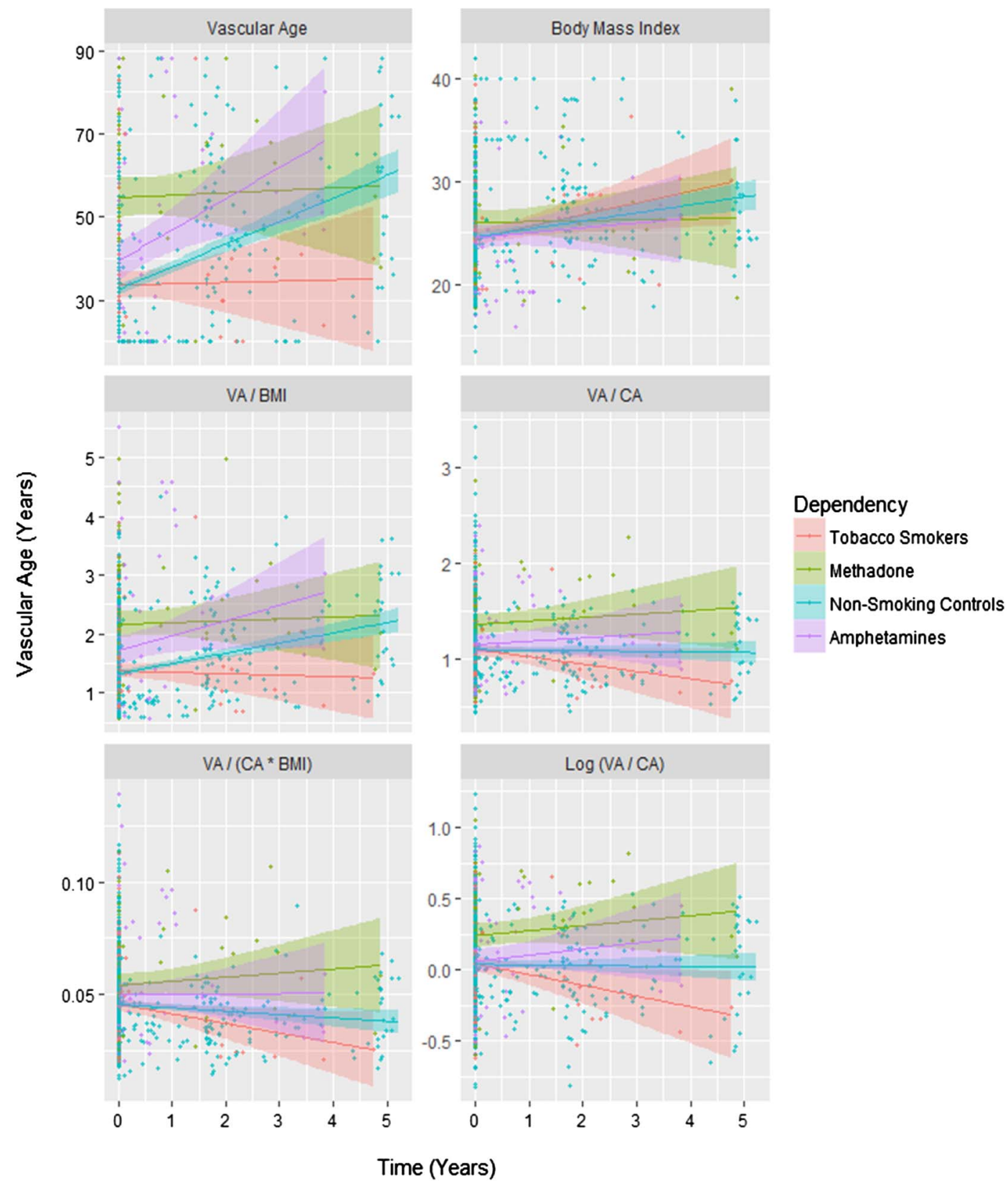

Figure 2 Vascular age by time and drug exposure type. BMI, body mass index; CA, chronological age.

have a potent suppressive effect on stem cell activity in almost all stem cell niches outside of the bone marrow. ${ }^{18-21}$

The cardiovascular toxicity of amphetamines includes myocardial infarction, ${ }^{22-28}$ cardiomyopathy, ${ }^{29}$ changes in epigenetic regulation and gene expression, ${ }^{17} 30$ refractory coronary vasospasm, ${ }^{31}$ mitochondriopathy, ${ }^{32}$ disruption of nitric oxide microvascular physiology and cerebrovascular signalling, ${ }^{33}$ cardiomyocyte apoptosis, ${ }^{34}$ endothelial cell toxicity, ${ }^{17} 35{ }_{36}$ alteration of redox status ${ }^{37}$ and induction of a cellular stress response. $^{38}$

Given the known cardiovascular toxicity of amphetaminetype stimulants, the present findings are in accordance with its known pharmacopathological profile. The consistency of data from the present report for an agent for which cardiovascular toxicity is well established has implications for the implementation of this methodology beyond this study and strengthens the proof of concept for use of this methodology with other drugs of abuse, and indeed in other pathophysiological conditions. Hence the current report substantially strengthens earlier reports from our group relating to the advanced cardiovascular, and by implication organismal ageing associated with opioid dependency ${ }^{63940}$ and also for cannabis abuse. $^{41}$

Our study is phenomenological and observational rather than mechanistic in its orientation which makes it difficult to dissect possible cellular pathways and processes from the data provided in the present report. As noted above, nephrotoxic and hyperglycaemic mechanisms seem unlikely from our regression data and they are not implicated in the bivariate between-group comparison data provided in online supplementary table S1. Innate 


\section{Original research}

Table 3 Linear regression of VA

\begin{tabular}{|c|c|c|c|c|c|c|c|c|}
\hline Parameter & Estimate & SE & t Value & p Value & Adj. $R^{2}$ & $\mathbf{F}$ & DF & Model P \\
\hline \multicolumn{9}{|c|}{ Cross-sectional model, regression of VA quadratic in CA } \\
\hline Age & 1.1622 & 0.0886 & 13.122 & $<0.0001$ & 0.4267 & 80.88 & 6.638 & $<0.0001$ \\
\hline$(\text { Age })^{2}$ & 1.1482 & 0.0917 & 12.519 & $<0.0001$ & & & & \\
\hline$(\text { Age })^{2}$ : tobacco & 0.5994 & 0.2300 & 2.606 & 0.0094 & & & & \\
\hline$(\mathrm{Age})^{2}$ : amphetamine & 0.8288 & 0.3582 & 2.314 & 0.0210 & & & & \\
\hline \multirow[t]{2}{*}{ Age: tobacco } & 0.2074 & 0.0954 & 2.173 & 0.0301 & & & & \\
\hline & \multicolumn{5}{|c|}{ Parameter values } & \multicolumn{3}{|c|}{ Model parameters } \\
\hline Parameter & Value & SE & DF & t Value & p Value & AIC & BIC & LogLik \\
\hline \multicolumn{9}{|c|}{ Longitudinal model, regression of VA quadratic in CA } \\
\hline Age & 1.2181 & 0.0835 & 205 & 14.5874 & $<0.0001$ & 395.0924 & 437.9048 & -188.5462 \\
\hline$(\text { Age })^{2}$ & 1.2253 & 0.0822 & 205 & 14.9025 & $<0.0001$ & & & \\
\hline Age: amphetamine & 0.2488 & 0.1074 & 205 & 2.3174 & 0.0215 & & & \\
\hline \multicolumn{9}{|c|}{ Longitudinal model, regression of VA/CA, cubic in CA } \\
\hline$(\mathrm{Age})^{2}: \mathrm{BMI}$ & -0.2086 & 0.0401 & 164 & -5.1965 & $<0.0001$ & 391.9747 & 536.0531 & -164.9874 \\
\hline$(\mathrm{Age})^{3}: \mathrm{BMI}$ & -0.1147 & 0.0347 & 164 & -3.3023 & 0.0012 & & & \\
\hline BMI & 0.2725 & 0.0882 & 164 & 3.0915 & 0.0023 & & & \\
\hline$(\text { Age })^{2}$ : Days: BMI: Amphetamine & -2.1703 & 0.8548 & 164 & -2.5391 & 0.0120 & & & \\
\hline Days: Amphetamine & 3.1828 & 1.2905 & 164 & 2.4664 & 0.0147 & & & \\
\hline Age: tobacco & 7.2217 & 2.9621 & 164 & 2.4380 & 0.0158 & & & \\
\hline Age: BMI: tobacco & -2.2018 & 0.9296 & 164 & -2.3686 & 0.0190 & & & \\
\hline$(\text { Age })^{3}$ : Days: BMI: Amphetamine & -0.7505 & 0.3333 & 164 & -2.2519 & 0.0257 & & & \\
\hline$(\text { Age })^{3}$ : days: BMI: non-smokers & 0.0130 & 0.0060 & 164 & 2.1683 & 0.0316 & & & \\
\hline
\end{tabular}

AIC, akaike information criterion; BIC, bayesian information criterion; BMI, body mass index; CA, chronological age; DF, degrees of freedom; LogLik, Log-Likelihood; VA, vascular age.

Figure 3 Vascular age (VA)/ chronological age (CA)_ratio by time after amphetamine exposure.
VA / CA by Time After Amphetamine Use - Logarithmic Smoother, 7 Days

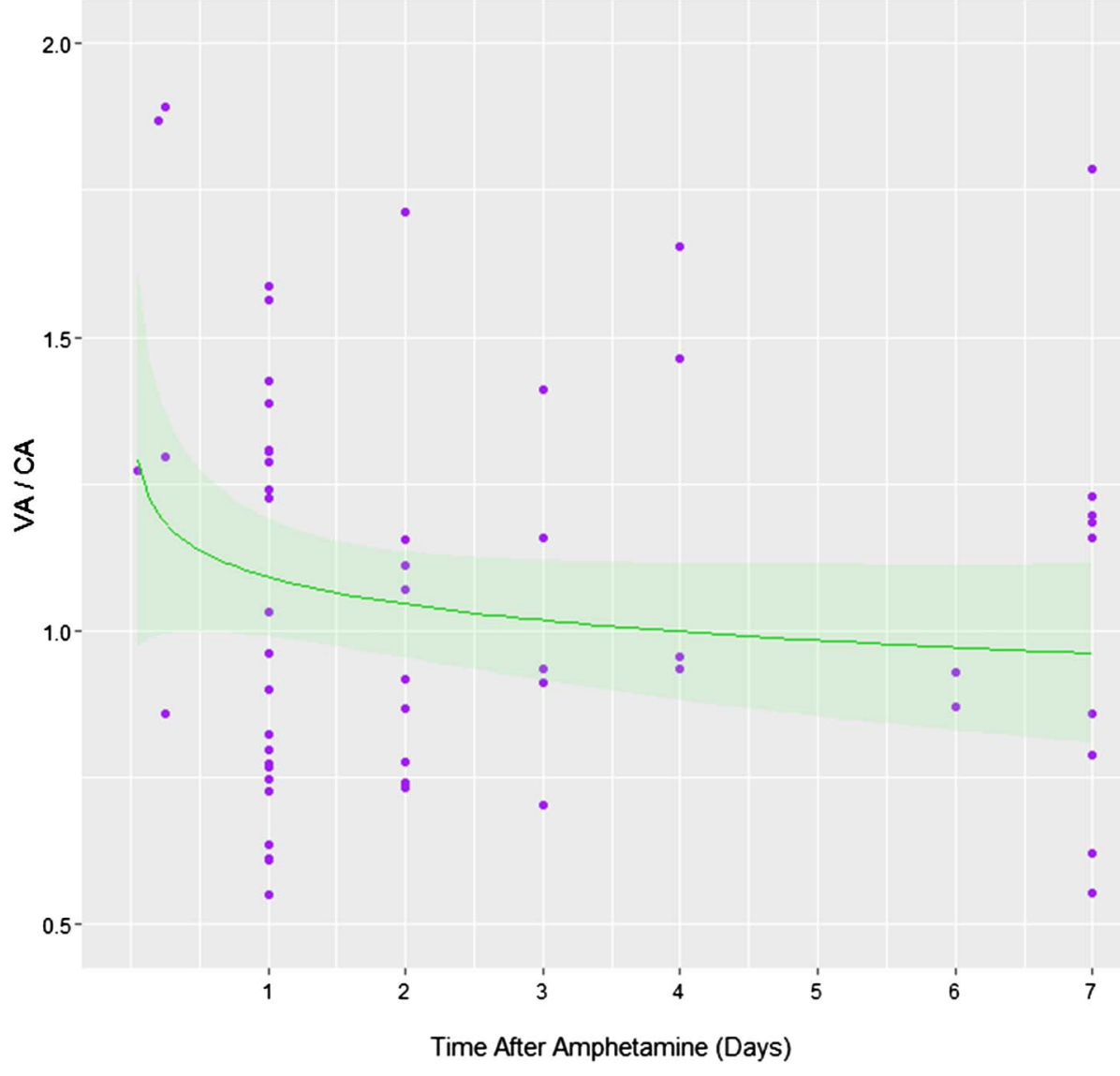


Table 4 Regression of VA/CA against time since amphetamine use

\begin{tabular}{|c|c|c|c|c|c|c|c|c|}
\hline \multirow[b]{2}{*}{ Parameter } & \multicolumn{5}{|c|}{ Parameter values } & \multicolumn{3}{|c|}{ Model parameters } \\
\hline & Value & SE & DF & t Value & $p$ Value & AIC & BIC & LogLik \\
\hline Age: amphetamine days & -0.0272 & 0.0110 & 12 & -2.4681 & 0.0296 & 68.5983 & 79.31406 & -29.2992 \\
\hline Age: days: amphetamine days & 0.0062 & 0.0029 & 12 & 2.1246 & 0.0551 & & & \\
\hline
\end{tabular}

AIC, akaike information criterion; BIC, bayesian information criterion; CA, chronological age; DF, degrees of freedom; RA, reference age.

Table 5 Linear regression of vascular age against cardiovascular system risk factors

\begin{tabular}{|c|c|c|c|c|c|c|c|c|}
\hline \multicolumn{9}{|c|}{ Longitudinal model, linear regression of chronological age } \\
\hline \multirow[b]{2}{*}{ Parameter } & \multicolumn{5}{|c|}{ Parameter values } & \multicolumn{3}{|c|}{ Model parameters } \\
\hline & Value & SE & DF & $\mathrm{t}$ Value & $\mathrm{p}$ Value & AIC & BIC & LogLik \\
\hline Age & 1.4237 & 0.2142 & 14 & 6.6458 & $<0.0001$ & 28.3553 & 47.8019 & -6.1777 \\
\hline Amphetamine & -0.4503 & 0.1000 & 70 & -4.5015 & $<0.0001$ & & & \\
\hline Systolic pressure & 1.5606 & 0.3339 & 14 & 4.6739 & 0.0004 & & & \\
\hline
\end{tabular}

AIC, akaike information criterion; BIC, bayesian information criterion; DF, degrees of freedom.

and adaptive immune processes have been heavily implicated by multiple reports both in atherogenesis ${ }^{4}{ }^{42-44}$ and ageing. ${ }^{45-47}$ Immune stimulation has also been noted to result from amphetamines by several authors ${ }^{35} 48-52$ as has amphetamine-induced hepatoxicity. ${ }^{53-56}$ The latter appears to be related in part to drug metabolism within the liver and the derivation of reactive metabolites. Moreover the bivariate comparison data in online supplementary table S1 do show significant between-group differences for the control and amphetamine groups in white cell count, absolute lymphocyte count, serum globulins and all the liver enzymes. However none of these markers survived model reduction when they were included in regression models. Hence the data provided herein are consistent with generalised activation of immune-metabolic processes underlying the observed acceleration of both atherosclerotic and ageing processes in amphetamine dependence. However formal demonstration of such mechanisms would have to await further prospective clinical studies and detailed explorations in model organisms.

This study has several strengths and some limitations which should be borne in mind. Strengths of the study include the direct comparison of drug dependent patients and normal controls within a single centre. Moreover several drug dependencies were available for comparison including tobacco, amphetamine and methadone. There are no other addiction medical clinics routinely applying central cardiovascular monitoring, to our knowledge, so this is also a strength. Moreover some sophisticated statistical modelling procedures have been employed in the data analysis phase which also supports the overall conclusions. Another study strength was the high degree of uniformity of the sex ratio between all four groups. Study weaknesses include the unavailability of dosing data which precluded the calculation of dose-response computations, and the lack of drug screening at the time of cardiovascular testing. As our sample size is not very large this would tend to limit the generalisability of our results somewhat. These issues represent refinements which could be addressed in future repetitions or replications of the study.

In conclusion this study has documented evidence of accelerated cardiovascular ageing in frequent users of amphetamines both over time and as a function of age which are consistent with either a subacute or subacute-on-chronic origin. It is of great concern that cardiovascular age relates directly to organismal age thereby implying accelerated biological ageing at the organismal level. These findings likely have implications at the macrovascular and microvascular, including stem cell, levels, given the widely recognise dependence of stem cell niches on microvascular activity and health. The present study reinforces the strength of similar studies with other dependency syndromes by strengthening the proof of concept of the methodology employed. It has also been shown that the ageing-accelerant effects of stimulant exposure are a power function of CA, with terms including interactions with the square and cube of CA reaching high levels of statistical significance. These findings therefore lend significance and a real sense of urgency to address the global psychostimulant epidemic and the swathe of

\section{Key messages}

What is already known about this subject?

Amphetamine abuse is well known to be causally associated with numerous major cardiovascular complications.

\section{What does this study add?}

We confirmed increased cardiovascular-biological age with amphetamine use in men and women, robust to adjustment for known cardiovascular risk factors, with effects beyond simply those due to acute exposure, and related to power functions (square and cubic functions) of chronological age.

\section{How might this impact on clinical practice?}

These findings confirm that amphetamine abuse is associated with acceleration of the organismal-biological age and the relationship with power functions of chronological age implies a feed-forward accelerating compounding relationship which underlies and exacerbates its cardiovascular and other toxicities. These findings imply an acceleration of the ageing process underlying the known described pathologies, and enhance our understanding of the nature of the human toxicology of amphetamine dependence. 
cardiovascular and neuropsychiatric conditions, including those degenerative disorders normally associated with more advanced CA, which accompany it.

Contributors ASR designed the study, treated the patients, conducted the RAPWT studies, analysed the data and wrote the initial draft of the paper. GKH gave advice on study design, and data analysis, wrote the paper and assisted with literature review. AN assisted with literature review and wrote the paper.

Competing interests None declared.

Ethics approval Southcity Medical Centre Human Research Ethics Committee.

Provenance and peer review Not commissioned; externally peer reviewed.

\section{REFERENCES}

1 United Nations Office of Drugs and Crime. World Drug Report 2013. Geneva: United Nations, 2013:1-151.

2 Darke S, Degenhardt L, Mattick R. Mortality amongst illicit drug users: epidemiology, causes and intervention. Sydney: Cambridge University Press, 2007:1-199.

3 Reece AS, Hulse GK. Elevation of central arterial stiffness and vascular ageing in opiate withdrawal: cross-sectional and longitudinal studies. Cardiovasc Toxicol 2013;13:55-67.

4 Lakatta EG, Wang M, Najjar SS. Arterial aging and subclinical arterial disease are fundamentally intertwined at macroscopic and molecular levels. Med Clin North Am 2009;93:583-604, Table of Contents.

5 Le Couteur DG, Lakatta EG. A vascular theory of aging. I Gerontol A Biol Sci Med Sci 2010:65:1025-7.

6 Reece AS, Hulse GK. Impact of opioid pharmacotherapy on arterial stiffness and vascular ageing: cross-sectional and longitudinal studies. Cardiovasc Toxicol 2013;13:254-66

7 Nelson MR, Stepanek J, Cevette M, et al. Noninvasive measurement of central vascular pressures with arterial tonometry: clinical revival of the pulse pressure waveform? Mayo Clin Proc 2010;85:460-72

8 Nichols WW, Denardo SJ, Wilkinson IB, et al. Effects of arterial stiffness, pulse wave velocity, and wave reflections on the central aortic pressure waveform. J Clin Hypertens (Greenwich) 2008;10:295-303.

9 O'Rourke MF, Nichols WW, Safar ME. Pulse waveform analysis and arterial stiffness: realism can replace evangelism and scepticism. J Hypertens 2004;22:1633-4; author reply 1634 .

10 Mereu M, Bonci A, Newman AH, et al. The neurobiology of modafinil as an enhancer of cognitive performance and a potential treatment for substance use disorders. Psychopharmacology (Berl) 2013;229:415-34.

11 Kienbaum $\mathrm{P}$, Thürauf $\mathrm{N}$, Michel MC, et al. Profound increase in epinephrine concentration in plasma and cardiovascular stimulation after mu-opioid receptor blockade in opioid-addicted patients during barbiturate-induced anesthesia for acute detoxification. Anesthesiology 1998;88:1154-61.

12 Okabe K, Kobayashi S, Yamada T, et al. Neurons limit angiogenesis by titrating VEGF in retina. Cell 2014;159:584-96.

13 Rafii S, Butler JM, Ding BS. Angiocrine functions of organ-specific endothelial cells. Nature 2016;529:316-25.

14 Lakatta EG. Arterial aging is risky. J Appl Physiol 2008;105:1321-2.

15 Powrozek TA, Sari Y, Singh RP, et al. Neurotransmitters and substances of abuse: effects on adult neurogenesis. Curr Neurovasc Res 2004;1:251-60.

$16 \mathrm{Xu}$ C, Loh HH, Law PY. Effects of addictive drugs on adult neural stem/progenitor cells. Cell Mol Life Sci 2016;73:327-48.

17 Fisher D, Gamieldien K, Mafunda PS. Methamphetamine is not Toxic but Disrupts the Cell Cycle of Blood-Brain Barrier Endothelial Cells. Neurotox Res 2015;28:8-17.

18 Campisi J. Senescent cells, tumor suppression, and organismal aging: good citizens, bad neighbors. Cell 2005;120:513-22.

19 Deverman BE, Patterson PH. Cytokines and CNS development. Neuron 2009:64:61-78.

20 Boulanger LM. Immune proteins in brain development and synaptic plasticity. Neuron 2009:64:93-109.

21 Carpentier PA, Palmer TD. Immune influence on adult neural stem cell regulation and function. Neuron 2009:64:79-92.

22 Westover AN, Halm EA. Do prescription stimulants increase the risk of adverse cardiovascular events?: A systematic review. BMC Cardiovasc Disord 2012;12:41.

23 Devlin RJ, Henry JA. Clinical review: Major consequences of illicit drug consumption. Crit Care 2008;12:202.

24 Bergstrom DL, Keller C. Drug-induced myocardial ischemia and acute myocardial infarction. Crit Care Nurs Clin North Am 1992;4:273-8.

25 Costa GM, Pizzi C, Bresciani B, et al. Acute myocardial infarction caused by amphetamines: a case report and review of the literature. Ital Heart J 2001;2:478-80

26 Choi YS, Pearl WR. Cardiovascular effects of adolescent drug abuse. J Adolesc Health Care 1989;10:332-7.

27 Waksman J, Taylor RN Jr, Bodor GS, et al. Acute myocardial infarction associated with amphetamine use. Mayo Clin Proc 2001;76:323-6.
$28 O^{\prime}$ Connor AD, Rusyniak DE, Bruno A. Cerebrovascular and cardiovascular complications of alcohol and sympathomimetic drug abuse. Med Clin North Am 2005;89:1343-58.

29 Jafari Giv M. Exposure to Amphetamines Leads to Development of Amphetamine Type Stimulants Associated Cardiomyopathy (ATSAC). Cardiovasc Toxicol Published Online First: 26 Sept 2016. doi:10.1007/s12012-016-9385-8

30 Koczor CA, Ludlow I, Hight RS II, et al. Ecstasy (MDMA) alters cardiac gene expression and DNA methylation: implications for circadian rhythm dysfunction in the heart. Toxicol Sci 2015;148:183-91.

31 Chen JP. Methamphetamine-associated acute myocardial infarction and cardiogenic shock with normal coronary arteries: refractory global coronary microvascular spasm. J Invasive Cardiol 2007;19:E89-92.

32 Barbosa DJ, Capela JP, Feio-Azevedo R, et al. Mitochondria: key players in the neurotoxic effects of amphetamines. Arch Toxicol 2015;89:1695-725.

33 Saengjaroentham C, Supornsilpchai W, Ji-Au W, et al. Serotonin depletion can enhance the cerebrovascular responses induced by cortical spreading depression via the nitric oxide pathway. Int I Neurosci 2015;125:130-9.

34 Leung KP, Qu YH, Qiao DF, et al. Critical role of insulin-like growth factor binding protein-5 in methamphetamine-induced apoptosis in cardiomyocytes. Mol Med Rep 2014;10:2306-12.

35 Kiyatkin EA, Sharma HS. Not just the brain: methamphetamine disrupts blood-spinal cord barrier and induces acute glial activation and structural damage of spinal cord cells. CNS Neurol Disord Drug Targets 2015;14:282-94.

36 Conant K, Lim ST, Randall B, et al. Matrix metalloproteinase dependent cleavage of cell adhesion molecules in the pathogenesis of CNS dysfunction with HIV and methamphetamine. Curr HIV Res 2012:10:384-91.

37 Emoto MC, Yamato M, Sato-Akaba H, et al. Brain imaging in methamphetamine-treated mice using a nitroxide contrast agent for EPR imaging of the redox status and a gadolinium contrast agent for MRI observation of blood-brain barrier function. Free Radic Res 2015;49:1038-47.

38 Navarro-Zaragoza J, Ros-Simó C, Milanés MV, et al. Binge Ethanol and MDMA Combination Exacerbates Toxic Cardiac Effects by Inducing Cellular Stress. PLoS One 2015;10:e0141502

39 Reece AS, Hulse GK. Reduction in arterial stiffness and vascular age by naltrexone-induced interruption of opiate agonism. BMJ Open 2013;3. pii: e002610.

40 Reece AS, Hulse GK. Impact of lifetime opioid exposure on arterial stiffness and vascular age: cross-sectional and longitudinal studies in men and women. BMJ Open 2014:4:e004521.

41 Reece AS, Norman A, Hulse GK. Cannabis exposure as an interactive cardiovascular risk factor and accelerant of organismal ageing: a longitudinal study. BMJ Open 2016:6:e011891.

42 Csiszar $A$, Wang M, Lakatta EG, et al. Inflammation and endothelial dysfunction during aging: role of NF-kappaB. J Appl Physiol 2008;105:1333-41.

43 Scuteri A, Orru M, Morrell C, et al. Independent and additive effects of cytokine patterns and the metabolic syndrome on arterial aging in the SardiNIA Study. Atherosclerosis 2011;215:459-64.

44 Narita M, Suzuki M, Kuzumaki N, et al. Implication of activated astrocytes in the development of drug dependence: differences between methamphetamine and morphine. Ann N Y Acad Sci 2008;1141:96-104.

45 Fauci AS, Braunwald E, Kapser DL, et al. eds. Harrison's principles of internal medicine. 17th edn. New York: McGraw Hill, 2008.

46 Hadley EC, Lakatta EG, Morrison-Bogorad M, et al. The future of aging therapies. Cell 2005;120:557-67.

47 Kirkwood TB. Understanding the odd science of aging. Cell 2005;120:437-47.

48 Cabral GA. Drugs of abuse, immune modulation, and AIDS. J Neuroimmune Pharmacol 2006:1:280-95.

49 Loftis JM, Janowsky A. Neuroimmune basis of methamphetamine toxicity. Int Rev Neurobiol 2014:118:165-97.

50 Pacifici R, Zuccaro P, Farré M, et al. Immunomodulating activity of MDMA. Ann N Y Acad Sci 2000;914:215-24.

51 Rubio-Araiz A, Perez-Hernandez M, Urrutia A, et al. 3,4-Methylenedioxymethamphetamine (MDMA, ecstasy) disrupts blood-brain barrier integrity through a mechanism involving P2X7 receptors. Int I Neuropsychopharmacol 2014;17:1243-55.

52 Hutchinson MR, Shavit Y, Grace PM, et al. Exploring the neuroimmunopharmacology of opioids: an integrative review of mechanisms of central immune signaling and their implications for opioid analgesia. Pharmacol Rev 2011:63:772-810.

53 Pateria P, de Boer B, MacQuillan G. Liver abnormalities in drug and substance abusers. Best Pract Res Clin Gastroenterol 2013;27:577-96.

54 Antolino-Lobo I, Meulenbelt J, van den Berg $\mathrm{M}$, et al. A mechanistic insight into 3,4-methylenedioxymethamphetamine ("ecstasy")-mediated hepatotoxicity. Vet $Q$ 2011:31:193-205.

55 Turillazzi E, Riezzo I, Neri M, et al. MDMA toxicity and pathological consequences: a review about experimental data and autopsy findings. Curr Pharm Biotechnol 2010;11:500-9.

56 Carvalho $\mathrm{M}$, Pontes $\mathrm{H}$, Remião $\mathrm{F}$, et al. Mechanisms underlying the hepatotoxic effects of ecstasy. Curr Pharm Biotechnol 2010;11:476-95. 